\title{
Chromatin landscapes and genetic risk in systemic lupus
}

\author{
Joyce S. Hui-Yuen ${ }^{1,2^{*+}}$, Lisha Zhu ${ }^{3+}$, Lai Ping Wong ${ }^{4}$, Kaiyu Jiang ${ }^{4}$, Yanmin Chen ${ }^{4}$, Tao Liu $^{5}$ and James N. Jarvis ${ }^{6}$
}

\begin{abstract}
Background: Systemic lupus erythematosus (SLE) is a multi-system, complex disease in which the environment interacts with inherited genes to produce broad phenotypes with inter-individual variability. Of 46 single nucleotide polymorphisms (SNPS) shown to confer genetic risk for SLE in recent genome-wide association studies, 30 lie within noncoding regions of the human genome. We therefore sought to identify and describe the functional elements (aside from genes) located within these regions of interest.

Methods: We used chromatin immunoprecipitation followed by sequencing to identify epigenetic marks associated with enhancer function in adult neutrophils to determine whether enhancer-associated histone marks were enriched within the linkage disequilibrium (LD) blocks encompassing the 46 SNPs of interest. We also interrogated available data in Roadmap Epigenomics for $\mathrm{CD}^{+} \mathrm{T}$ cells and $\mathrm{CD} 19^{+} \mathrm{B}$ cells to identify these same elements in lymphoid cells.

Results: All three cell types demonstrated enrichment of enhancer-associated histone marks compared with genomic background within LD blocks encoded by SLE-associated SNPs. In addition, within the promoter regions of these LD blocks, all three cell types demonstrated enrichment for transcription factor binding sites above genomic background. In CD19+ B cells, all but one of the LD blocks of interest were also enriched for enhancer-associated histone marks.

Conclusions: Much of the genetic risk for SLE lies within or near genomic regions of disease-relevant cells that are enriched for epigenetic marks associated with enhancer function. Elucidating the specific roles of these noncoding elements within these cell-type-specific genomes will be crucial to our understanding of SLE pathogenesis.
\end{abstract}

Keywords: Systemic lupus erythematosus, Genetics, Enhancers, Neutrophils, Lymphocytes,

\section{Background}

Systemic lupus erythematosus (SLE) is a complex trait believed to be caused by gene-environment interactions that lead to a perturbed immunologic state in which autoantibodies, immune complex deposition, and complement activation contribute to systemic inflammation and target tissue damage. The genetics of systemic lupus has been studied extensively, in particular its association with complement deficiencies. Although rare, C1q deficiency is the strongest genetic risk factor for $\operatorname{SLE}[1,2]$.

\footnotetext{
*Correspondence: jhuiyuen@nshs.edu

${ }^{\dagger}$ Equal contributors

'Division of Pediatric Rheumatology, Steven and Alexandra Cohen Children's Medical Center, 1991 Marcus Avenue, Suite M100, Lake Success, NY 11042, USA

${ }^{2}$ Department of Pediatrics, Hofstra-Northwell School of Medicine, Hempstead, NY 11549, USA

Full list of author information is available at the end of the article
}

C1r and C1s deficiencies are commonly inherited together, and over $50 \%$ of these patients develop SLE [3]. Moreover, homozygous $\mathrm{C} 2$ and $\mathrm{C} 4$ deficiencies have been shown to predispose toward SLE [4-6].

Other than complement deficiencies, however, associations between SLE and functions of specific genes have been harder to clarify. This situation became even more confusing as data began to emerge from genome-wide association studies (GWAS) and genetic fine mapping studies [7-9], where the majority of risk-associated single nucleotide polymorphisms (SNPs) occurred in noncoding regions of the genome, often considerable distances (in genomic terms) from protein-coding genes and their promoters. Thus, while it is still common in the literature to identify disease-associated SNPs by their nearest gene, most genetic risk for SLE does not appear 
to be within "genes," as conventionally understood, at all. In this respect, SLE resembles almost every other complex trait studied by GWAS [10]. Maurano et al. [10] have shown that most SNPs for most complex traits lie within genomic regions identified by projects like ENCODE, Roadmap Epigenomics, and Blueprint Epigenomics as regulatory regions, often regions active during fetal life. This observation has been confirmed from studies of specific diseases. Recently, for example, Jiang et al. [11] demonstrated that regions of genetic risk for juvenile idiopathic arthritis (JIA) identified by genetic fine mapping using Illumina Immunochip arrays are enriched for H3K4me1 and or H3K27ac histone marks, epigenetic signatures associated with enhancer function. There is thus a broadly emerging consensus in the fields of genetics and functional genomics that genetic risk for complex traits likely involves specific aspects of transcriptional regulation and coordination rather than aberrant function of protein-coding genes.

In the current study, we examined the "epigenetic landscape" around known SLE-associated SNPs in an effort to better understand the potential significance of disease-associated SNPs. We focused on three cell types known to contribute to SLE pathogenesis: $\mathrm{CD} 19^{+} \mathrm{B}$ cells, $\mathrm{CD} 4^{+} \mathrm{T}$ cells, and neutrophils [12-16]. We used ENCODE and Roadmap Epigenomics data as well as data generated in our own laboratory (for neutrophils) to identify functional elements within these regions.

\section{Methods}

We queried the chromatin landscape around SNPs whose associations with SLE are well documented [17]. In addition, we queried recently reported SNPs found in a large Asian population [18]. CD19 ${ }^{+} \mathrm{B}$-cell and $\mathrm{CD} 4^{+} \mathrm{T}$-cell data were queried from ENCODE, while neutrophil RNA sequencing (RNAseq) and chromatin immunoprecipitation sequencing (ChIP-seq) data for H3K4me1/H3K27ac data were generated in our laboratory and have been reported recently [11]. Laboratory methods for ChIP-seq and RNAseq data are described briefly in the following.

\section{Healthy adults}

Enhancers are both cell specific and cell-state specific [19]. Because neutrophils were not among the cells studied in either the ENCODE or Roadmap Epigenomics projects, we sought to create a genomic map for enhancer element locations using normal adult neutrophils. We obtained neutrophils from three healthy adults aged 25-40 using techniques we have described previously [11].

\section{Chromatin immunoprecipitation for histone marks H3K4me1 and H3K27ac and sequencing}

Neutrophils were isolated as described previously [20]. The ChIP assay was carried out according to the protocol of the manufacturer (Cell Signaling Technologies Inc., Danvers, MA, USA) and has been described in our work published previously [11]. Briefly, adult neutrophils were incubated with newly prepared $1 \%$ formaldehyde in PBS at room temperature (RT). Crosslinking was quenched by adding $1 \times$ glycine. The crosslinked samples were centrifuged, the supernatant discarded, and the pellet washed with cold PBS followed by resuspension in $10 \mathrm{ml}$ ice-cold Buffer A plus DTT, PMSF, and protease inhibitor cocktail. Cells were incubated on ice and then centrifuged at $4{ }^{\circ} \mathrm{C}$ to precipitate nucleus pellets, which were then resuspended in $10 \mathrm{ml}$ ice-cold Buffer A plus DTT. The nucleus pellet was incubated with Micrococcal nuclease for 20 minutes at $37{ }^{\circ} \mathrm{C}$ with frequent mixing to digest DNA. Sonication of nuclear lysates was performed using a Sonic Dismembrator (FB705; Fisher Scientific, Pittsburgh, PA, USA) on ice. After centrifugation of sonicated lysates, the supernatant was transferred into a fresh tube. Fifty microliters of the supernatant (chromatin preparation) was taken to analyze chromatin digestion and concentration. Fifteen micrograms of chromatin was added into $1 \times$ ChIP buffer plus protease inhibitor cocktail to a total volume of $500 \mu \mathrm{l}$. After removal of $2 \%$ of chromatin as the input sample, the antibodies were added to the ChIP buffer. The antibodies against respective histone modifications were rabbit polyclonal antibodies against histone $\mathrm{H} 3$ acetylated at lysine 27 (H3K27ac) and histone H3 monomethylated at lysine 4 (H3K4me1) from Cell Signaling Technologies. The negative control was normal IgG (Cell Signaling Technologies). After immunoprecipitation, the magnetic beads were added and incubated for another 2 hours at $4{ }^{\circ} \mathrm{C}$. The magnetic beads are covalently coupled to a truncated form of recombinant protein G. They were then collected with a magnetic separator (Life Technologies, Grand Island, NY, USA). The beads were washed sequentially with low and high salt wash buffer, followed by incubation with elution buffer to elute protein/DNA complexes and reverse crosslinks of protein/DNA complexes to release DNA. The DNA fragments were purified by spin columns and dissolved in the elution buffer. The crosslinks of input sample were also reversed in elution buffer containing proteinase $\mathrm{K}$ before purification with spin columns. DNA sequencing was then conducted using the Illumina HiSeq 2500 at the next-generation sequencing center in University at Buffalo.

\section{ChIP-seq analysis of neutrophils}

Analysis of the ChIP-seq data was carried out exactly as described previously [11]. MACS2 v2.1.10 [21] was applied for calling regions enriched with histone marks against the input sample, with the parameters "- 
nomodel -extsize 150 -broad -broad-cutoff 0.1". Details of these analyses are further described by Jiang et al. [11].

\section{CD19 ${ }^{+}$B-cell and $\mathrm{CD} 4^{+}$T-cell analysis}

In order to compare data from neutrophils with existing data from $\mathrm{CD} 19^{+} \mathrm{B}$ cells and $\mathrm{CD} 4^{+} \mathrm{T}$ cells, we queried data generated from the Roadmap Epigenomics Project [22]. Raw ChIP-seq data for $\mathrm{CD} 19^{+}$primary cells were downloaded from the GEO database [23] [GEO:GSM1027296, GEO:GSM1027287, GEO:GSM102 7300, GEO:GSM1027304] for H3K4me1, H3K27ac, H3K4me3, and input control respectively. Raw ChIP-seq data for $\mathrm{CD}^{+}{ }^{+} \mathrm{T}$ cells were downloaded [GEO:GSM12 20567, GEO:GSM1220560, GEO:GSM1102798, GEO: GSM1102805] for H3K4me1, H3K27ac, H3K4me3, and input control respectively. The methods for mapping and region-calling are the same as those was used to analyze neutrophil data.

\section{ENCODE transcription factor binding site enrichment}

ENCODE transcription factor binding site (TFBS) data were downloaded from UCSC Genome Browser ENCODE (http://hgdownload.cse.ucsc.edu/goldenPath/hg19/encodeDCC/wgEncodeRegTfbsClustered/). Only the TFBS information derived from blood cells was used for analysis. The whole genome was binned to $100 \mathrm{bp}$ bins and intersected with H3K27ac, H3K4me1, or H3K4me3 peak regions, which were used as background. Fisher's exact test was applied to test the significance of enrichment for TFBS for each transcription factor (TF) within H3K27ac, H3K4me1, or H3K4me3 peaks within linkage disequilibrium (LD) blocks compared with peak regions in the whole genome. The cutoff point for the false discovery rate (FDR) was set to 0.05 .

\section{Results}

\section{Association of regions of genetic risk with functional} elements within neutrophil genomes

We searched the LD regions near (within $5 \mathrm{~kb}$ of) each GWAS index locus for association with histone marks from ChIP-seq. LD blocks were defined for 46 out of the 58 SNPs described in recent GWAS $[17,18]$ using information from the SNAP database (http://www.broadinstitute.org/mpg/snap) [24] by querying data from the 1000 Genomes Project pilot and the HapMap3 database. LD blocks were defined using $r^{2}<0.9$.

We further investigated H3K4me1, H3K4me3, and H3K27ac distal regions relative to transcription start sites. The distal regions typically correspond to cis-acting enhancers located far away from the gene(s) they regulate [25]. Regions containing at least one methylated (H3K4me1 or H3K4me3) and one acetylated histone mark (H3K27ac) were referred to as active enhancers, and those that contained only one methylated histone group or $\mathrm{H} 3 \mathrm{~K} 27 \mathrm{ac}$ region were referred to as poised enhancers or H3K27ac-active enhancers, respectively. Of note, H3K4me3 appears to be cell-type specific, expressed in cells of the lymphoid lineage, and noted to be an important histone mark for enhancer activity [26].

We found functional elements within $5 \mathrm{~kb}$ of 36 of the 46 SNPs in adult neutrophils. Epigenetic evidence for active enhancers were found in 29 LD blocks, poised enhancers in six LD blocks, and H3K27ac-active enhancers in one LD block (Table 1). Using Fisher's exact test, these regions were significantly enriched for enhancer activity above the genomic background $(p<0.05)$ (Fig. 1).

\section{Enhancer elements within $\mathrm{CD} 4^{+} \mathrm{T}$ and $\mathrm{CD} 19^{+} \mathrm{B}$ cells}

Using the same approaches as we used for neutrophils, we interrogated available H3K4me1, H3K4me3, and H3K27ac ChIP-seq data from the Roadmap Epigenomics project for $\mathrm{CD} 4^{+} \mathrm{T}$ and $\mathrm{CD} 19^{+} \mathrm{B}$ cells. We found considerable overlap for the locations of H3K4me1 and H3K27ac peaks between our neutrophil data and resting $\mathrm{CD}^{+} \mathrm{T}$ cells. Functional elements were found within 39 of the 46 SNPs of interest in $\mathrm{CD}^{+} \mathrm{T}$ cells. Epigenetic evidence for active enhancers was found in $30 \mathrm{LD}$ blocks, and for poised enhancers in nine LD blocks; no LD blocks contained H3K27ac marks alone (Table 2).

In $\mathrm{CD} 19^{+} \mathrm{B}$ cells, we identified functional elements found in 42 of 46 SNPs of interest. Epigenetic evidence for active enhancers was present in $32 \mathrm{LD}$ blocks, and for poised enhancers in 10 LD blocks; no LD blocks contained H3K27ac histone marks alone (Table 3). There are thus more SNPs of interest in SLE with functional elements within lupus-associated LD blocks in $\mathrm{CD}_{1} 9^{+}$cells than in either $\mathrm{CD} 4^{+}$cells or neutrophils $(p<0.05)$. Representative screenshots from the UCSC Genome Browser with two of the LD blocks of interest are shown in Fig. 2.

While it is difficult at this time to determine exact differences in the acetylation and methylation of patients with SLE compared with healthy controls due to the scarcity of available data, we did perform an analysis of differentially methylated regions as identified by Absher et al. [27] in adult SLE patients. This analysis revealed only one gene (PBX2, on chromosome 6) lying within the same LD block as rs1270942 to be aberrantly methylated in T cells, B cells, and/or monocytes in SLE patients. In addition, analysis of differentially methylated regions identified by Coit et al. [28] in the neutrophils of adult SLE patients compared with healthy adult data from our laboratory 
Table 1 Histone marks in the SNP linkage disequilibrium blocks in neutrophils

\begin{tabular}{|c|c|c|c|c|c|}
\hline $\begin{array}{l}\text { GWAS index } \\
\text { SNP }\end{array}$ & Chr & $\begin{array}{l}\text { Linkage } \\
\text { disequilibrium } \\
\text { blocks }\end{array}$ & $\begin{array}{l}\text { Number of } \\
\text { H3K27ac } \\
\text { marks }\end{array}$ & $\begin{array}{l}\text { Number of } \\
\text { H3K4me1 } \\
\text { marks }\end{array}$ & $\begin{array}{l}\text { Enhancer } \\
\text { marks } \\
\text { (yes/no) }\end{array}$ \\
\hline rs10028805 & 4 & $102736456-102762581$ & 0 & 0 & No \\
\hline rs10036748 & 5 & $150457485-150461049$ & 55 & 388 & Yes \\
\hline rs10488631 & 7 & $128585616-128711874$ & 104 & 468 & Yes \\
\hline rs1059312 & 12 & $129277164-129288534$ & 44 & 84 & Yes \\
\hline rs10774625 & 12 & $111884608-112007756$ & 178 & 368 & Yes \\
\hline rs10807150 & 6 & $35154315-35278796$ & 160 & 263 & Yes \\
\hline rs10936599 & 3 & $169477506-169528523$ & 41 & 58 & Yes \\
\hline rs11644034 & 16 & $85967285-85980534$ & 0 & 24 & Yes \\
\hline rs11889341 & 2 & $191943742-191970120$ & 0 & 0 & No \\
\hline rs 12022418 & 1 & $192521591-192535107$ & 17 & 45 & Yes \\
\hline rs1270942 & 6 & $31704294-32175415$ & 126 & 0 & Yes \\
\hline rs12802200 & 11 & $566936-567627$ & 0 & 39 & Yes \\
\hline rs1610555 & 18 & 67523453-67544046 & 0 & 0 & No \\
\hline rs1801274 & 1 & $161470042-161479745$ & 36 & 317 & Yes \\
\hline rs1885889 & 13 & $100084234-100104106$ & 25 & 53 & Yes \\
\hline rs2009453 & 11 & $65399528-65405300$ & 78 & 237 & Yes \\
\hline rs223881 & 16 & 57386566-57317134 & 0 & 0 & No \\
\hline rs2286672 & 17 & $4706123-4712617$ & 0 & 3 & Yes \\
\hline rs2289583 & 15 & 75285114-75370012 & 227 & 386 & Yes \\
\hline rs2305772 & 19 & $52021247-52034940$ & 0 & 0 & No \\
\hline rs2421184 & 5 & 158884119-158886939 & 0 & 0 & No \\
\hline rs2431697 & 5 & 159879978-159883217 & 0 & 0 & No \\
\hline rs2476601 & 1 & $114303808-114377568$ & 113 & 297 & Yes \\
\hline rs2663052 & 10 & $50045456-50081232$ & 0 & 0 & No \\
\hline rs2732549 & 11 & $35073852-35098193$ & 26 & 106 & Yes \\
\hline rs2736340 & 8 & $11337587-11353000$ & 0 & 0 & No \\
\hline rs2941509 & 17 & 37885383-38077485 & 308 & 693 & Yes \\
\hline rs3024505 & 1 & 206939904-206943968 & 0 & 66 & Yes \\
\hline rs34572943 & 16 & $31272353-31276811$ & 79 & 150 & Yes \\
\hline rs3768792 & 2 & 213871709-213890232 & 0 & 0 & No \\
\hline rs3794060 & 11 & $71138710-71203790$ & 62 & 125 & Yes \\
\hline rs4917014 & 7 & 50278187-50308811 & 66 & 65 & Yes \\
\hline rs4948496 & 10 & 63803472-63819903 & 67 & 83 & Yes \\
\hline rs61616683 & 22 & 39747050-39756650 & 0 & 22 & Yes \\
\hline rs6568431 & 6 & 106574794-106597639 & 15 & 15 & Yes \\
\hline rs6740462 & 2 & 65654364-65667272 & 26 & 35 & Yes \\
\hline rs6932056 & 6 & $138132123-138243700$ & 175 & 286 & Yes \\
\hline rs740840 & 12 & 6327008-63600683 & 38 & 86 & Yes \\
\hline rs7444 & 22 & 21920817-21983260 & 153 & 420 & Yes \\
\hline rs7556469 & 1 & 198607998-198637582 & 379 & 487 & Yes \\
\hline rs7726414 & 5 & 133232663-13877357 & 252 & 1090 & Yes \\
\hline rs7941765 & 11 & $128499000-128500215$ & 59 & 99 & Yes \\
\hline rs849142 & 7 & 28162674-28200097 & 17 & 222 & Yes \\
\hline
\end{tabular}

and available in Roadmap Epigenomics revealed that none of these regions were located within the LD blocks containing the SLE-associated SNPs. Less than $40 \%$ of these regions contained enhancer marks in healthy adult neutrophils. Fewer than $1 / 3$ of these regions contained enhancer marks in healthy adult $\mathrm{CD} 4^{+}$and $\mathrm{CD} 19^{+}$cells.

\section{Transcription factor binding sites at enhancer regions in LD blocks in $\mathrm{CD}^{+}$cells, $\mathrm{CD} 19^{+}$cells, and neutrophils}

We next sought to further test the likely functional significance of H3K4me1, H3K4me3, and H3K27ac enrichment within the SLE-associated LD blocks. We therefore analyzed the TF ChIP-seq data from blood cells obtained from the UCSC Genome Browser ENCODE data portal [29] to determine whether there was significant enrichment for TF binding within the enhancer regions located within SLE-associated LD blocks compared with other regions (Fig. 3). We investigated both promoter and nonpromoter regions within the regions where histone marks (H3K4me1, H3K4me3, and H3K27ac) are associated with enhancer activities. As expected, promoter regions within these LD blocks (defined as $(-5 \mathrm{~K}, 1 \mathrm{~K})$ of transcription start sites) are highly enriched for TF binding sites. Furthermore, we identified more enrichment for TF binding sites in H3K4me3 peak regions than in either H3K27ac or H3K4me1 peak regions in promoter sites in $\mathrm{CD}_{1} 9^{+}$and $\mathrm{CD}_{4}^{+} \mathrm{T}$ cells $(p<0.05)$. Overall, the LD blocks containing lupus-associated SNPs appeared to be in active, dynamic regions of leukocyte genomes as determined by the abundance of transcription factor binding motifs within these regions

Of note, 23 out of 46 SNP regions have shared histone modifications in all three cell types investigated. There are 102 genes located within the 46 SNP LD blocks, which are involved in 26 Panther pathways, including T-cell and B-cell activation, and Jak/STAT signaling pathways (Additional file 1: Table S1). Moreover, Farh et al. [30] demonstrated that many causal variants which map to immune-cell enhancers may gain histone acetylation and transcribe enhancer-associated RNA upon immune stimulation. This could indicate that the majority 

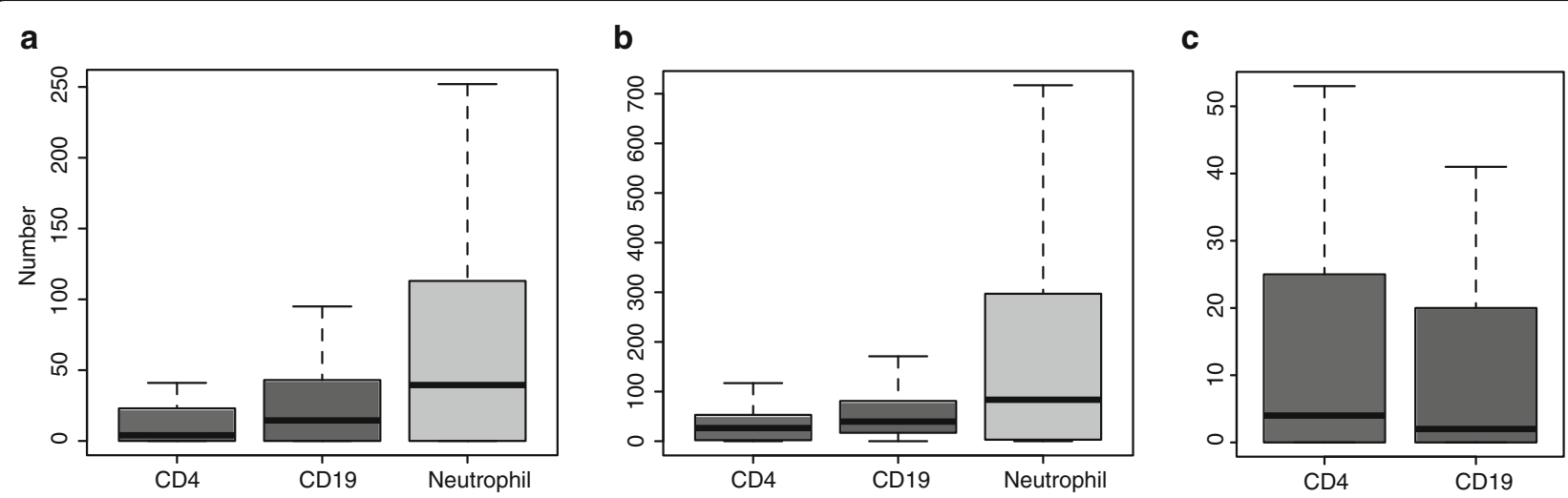

Fig. 1 Number of $\mathrm{H} 3 \mathrm{~K} 27 \mathrm{ac}, \mathrm{H} 3 \mathrm{~K} 4 \mathrm{me1}$, and $\mathrm{H} 3 \mathrm{~K} 4 \mathrm{me} 3$ peak regions (histone marks) in linkage disequilibrium blocks. a Box plot of the raw number of $\mathrm{H} 3 \mathrm{~K} 27 \mathrm{ac}$ regions in $\mathrm{CD}^{+}$cells, CD19 ${ }^{+}$cells, and neutrophils. b Box plot of the raw number of H3K4me1 regions in CD4 ${ }^{+}$cells, CD19 cells, and neutrophils. c Box plot of the raw number of H3K4me3 regions in $\mathrm{CD}^{+}$and $\mathrm{CD} 19^{+}$cells

of SNPs are functional SNPs. However, expression quantitative loci analysis (eQTL) revealed that only one SNP (rs2736340) was associated with a target gene (FAM167A). Similarly, when the SNPs of interest were compared with genes identified by Bennett et al [31]. whose expression was upregulated in SLE patients, only one gene was found to lie in the same LD block as one of the identified SNPs: a phorbolin-1 like gene from the interferon family lies in the same LD block as SNP rs61616683.

\section{Discussion}

Multiple GWAS in human disease have yielded surprising data demonstrating that a significant majority of disease-associated polymorphisms are located within noncoding regions of the genome $[8,9]$, i.e., those regions of the genome where transcription is coordinated on a genome-wide basis [32]. In fact, only $1-2 \%$ of the human genome is believed to span protein-coding genes $[33,34]$ and the remaining DNA is believed to incorporate an abundance of regulatory elements that contribute to maintenance of a cell's identity and/or regulate specific cell functions.

Results of recent GWAS in SLE also illustrate this point. Of 46 SNPs identified by Bentham et al. and Sun et al. $[17,18]$ as conferring risk for SLE, only 16 lie within coding regions. In this study, we demonstrate that these SLE-associated SNPs lie within LD blocks containing histone marks commonly associated with enhancer function. We identified these marks in three cell types known to contribute to SLE pathogenesis and/or disease manifestations: $\mathrm{CD}_{4}^{+} \mathrm{T}$ cells, $\mathrm{CD} 19^{+} \mathrm{B}$ cells, and neutrophils.

Enhancers are cis-acting, active regions of DNA that promote gene transcription. Enhancers act by binding transcription factors and other transcriptional regulators that then alter the three-dimensional conformation of chromatin and facilitate the interaction between gene promoters and protein-DNA complexes. Enhancers may lie considerable distances from the promoters they regulate and may not regulate the genes closest to them [35]. Enhancers may also be cell-type specific and tissue specific, and may regulate more than one gene $[19,36]$. For example, Martin et al. [35] recently used $\mathrm{HiC}$ chromosome capture approaches to identify long-range interactions between autoimmune disease risk loci and target genes. They demonstrated that SNPs lying large distances apart (in genomic terms) might either interact with the nearest gene or bypass multiple genes lying nearer to them to interact with those situated more distally.

The finding that the genetic risk for SLE lies largely within functional, noncoding regions of the human genome that contain regulatory elements in neutrophils, $\mathrm{CD} 4^{+} \mathrm{T}$ cells, and $\mathrm{CD} 19^{+} \mathrm{B}$ cells invites a new perspective in disease pathogenesis. All three cell types have been implicated in the pathogenesis of SLE [12-16]. Preliminary studies in adult SLE used RNAseq and found differentially expressed genes comprising different cellular functions from distinct leukocyte populations (in particular, from B cells and monocytes) [37]. Thus, cell-type-specific differences in gene expression may contribute to the pathogenesis of SLE. Similar findings of risk in the noncoding genome have been observed in the neutrophils and $\mathrm{CD} 4^{+}$ $\mathrm{T}$ cells of JIA patients [11].

Our results demonstrate that, particularly in lymphocytes, there is copious transcription factor binding in H3K4me1/H3K4me3/H327ac-marked regulatory regions encompassed by the LD blocks containing SLEassociated SNPs, providing further evidence that these are important regulatory regions. Shi et al. [38] have 
Table 2 Histone marks in the SNP linkage disequilibrium blocks in CD4 ${ }^{+} \mathrm{T}$ cells

\begin{tabular}{|c|c|c|c|c|c|c|}
\hline $\begin{array}{l}\text { GWAS index } \\
\text { SNP }\end{array}$ & Chr & $\begin{array}{l}\text { Linkage disequilibrium } \\
\text { blocks }\end{array}$ & $\begin{array}{l}\text { Number of } \\
\text { H3K27ac marks }\end{array}$ & $\begin{array}{l}\text { Number of } \\
\text { H3K4me1 marks }\end{array}$ & $\begin{array}{l}\text { Number of } \\
\text { H3K4me3 marks }\end{array}$ & $\begin{array}{l}\text { Enhancer marks } \\
\text { (yes/no) }\end{array}$ \\
\hline rs10028805 & 4 & $102736456-102762581$ & 0 & 0 & 0 & No \\
\hline rs10036748 & 5 & $150457485-150461049$ & 18 & 35 & 22 & Yes \\
\hline rs10488631 & 7 & $128585616-128711874$ & 11 & 30 & 14 & Yes \\
\hline rs1059312 & 12 & $129277164-129288534$ & 2 & 19 & 0 & Yes \\
\hline rs10774625 & 12 & $111884608-112007756$ & 2 & 15 & 0 & Yes \\
\hline rs10807150 & 6 & $35154315-35278796$ & 89 & 116 & 53 & Yes \\
\hline rs10936599 & 3 & $169477506-169528523$ & 30 & 22 & 36 & Yes \\
\hline rs11644034 & 16 & $85967285-85980534$ & 13 & 31 & 6 & Yes \\
\hline rs11889341 & 2 & $191943742-191970120$ & 0 & 9 & 0 & Yes \\
\hline rs12022418 & 1 & $192521591-192535107$ & 0 & 0 & 0 & No \\
\hline rs1270942 & 6 & $31704294-32175415$ & 29 & 69 & 228 & Yes \\
\hline rs12802200 & 11 & $566936-567627$ & 0 & 0 & 0 & No \\
\hline rs1610555 & 18 & $67523453-67544046$ & 0 & 1 & 0 & Yes \\
\hline rs1801274 & 1 & $161470042-161479745$ & 0 & 0 & 6 & Yes \\
\hline rs1885889 & 13 & 100084234-100104106 & 20 & 38 & 10 & Yes \\
\hline rs2009453 & 11 & 65399528-65405300 & 5 & 17 & 3 & Yes \\
\hline rs223881 & 16 & $57386566-57317134$ & 0 & 0 & 0 & No \\
\hline rs2286672 & 17 & $4706123-4712617$ & 0 & 7 & 7 & Yes \\
\hline rs2289583 & 15 & $75285114-75370012$ & 4 & 66 & 14 & Yes \\
\hline rs2305772 & 19 & $52021247-52034940$ & 0 & 0 & 0 & No \\
\hline rs2421184 & 5 & $158884119-158886939$ & 0 & 3 & 0 & Yes \\
\hline rs2431697 & 5 & 159879978-159883217 & 0 & 0 & 0 & No \\
\hline rs2476601 & 1 & $114303808-114377568$ & 65 & 53 & 25 & Yes \\
\hline rs2663052 & 10 & $50045456-50081232$ & 0 & 0 & 0 & No \\
\hline rs2732549 & 11 & $35073852-35098193$ & 23 & 47 & 0 & Yes \\
\hline rs2736340 & 8 & $11337587-11353000$ & 0 & 2 & 11 & Yes \\
\hline rs2941509 & 17 & $37885383-38077485$ & 228 & 342 & 116 & Yes \\
\hline rs3024505 & 1 & 206939904-206943968 & 1 & 47 & 0 & Yes \\
\hline rs34572943 & 16 & $31272353-31276811$ & 0 & 11 & 0 & Yes \\
\hline rs3768792 & 2 & 213871709-213890232 & 0 & 0 & 2 & Yes \\
\hline rs3794060 & 11 & $71138710-71203790$ & 14 & 29 & 28 & Yes \\
\hline rs4917014 & 7 & $50278187-50308811$ & 59 & 59 & 5 & Yes \\
\hline rs4948496 & 10 & 63803472-63819903 & 41 & 53 & 27 & Yes \\
\hline rs61616683 & 22 & $39747050-39756650$ & 0 & 0 & 0 & No \\
\hline rs6568431 & 6 & 106574794-106597639 & 4 & 34 & 0 & Yes \\
\hline rs6740462 & 2 & $65654364-65667272$ & 0 & 28 & 28 & Yes \\
\hline rs6932056 & 6 & $138132123-138243700$ & 97 & 117 & 53 & Yes \\
\hline rs740840 & 12 & 6327008-63600683 & 1 & 25 & 0 & Yes \\
\hline rs7444 & 22 & 21920817-21983260 & 5 & 133 & 13 & Yes \\
\hline rs7556469 & 1 & 198607998-198637582 & 166 & 41 & 126 & Yes \\
\hline
\end{tabular}


Table 2 Histone marks in the SNP linkage disequilibrium blocks in CD4 ${ }^{+} \mathrm{T}$ cells (Continued)

\begin{tabular}{lllllll}
\hline rs7726414 & 5 & $133232663-13877357$ & 309 & 809 & 318 & Yes \\
rs7941765 & 11 & $128499000-128500215$ & 8 & 9 & 2 & Yes \\
rs849142 & 7 & $28162674-28200097$ & 1 & 25 & 110 & Yes \\
rs9462027 & 6 & $34563164-34828553$ & 68 & 96 & Yes \\
rs9652601 & 16 & $11164567-11207894$ & 9 & 78 & 0 & Yes \\
rs9782955 & 1 & $235907825-236041129$ & 22 & 33 & 24 & Yes \\
\hline
\end{tabular}

Linkage disequilibrium blocks were obtained from the 1000 Genomes Project pilot 1 and/or HapMap3 database

$\mathrm{Chr}$ chromosome, GWAS genome wide association studies, SNP single nucleotide polymorphism

shown that both promoters and enhancers exhibit significant changes in monocytes from SLE patients when compared with healthy controls. In particular, differentially methylated regions in SLE were significantly enriched in potential interferon-related TFBS. Furthermore, the importance of histone modifications (e.g., epigenetic marks) in regulating transcription is demonstrated in the recent work of Zhang et al. These authors identified distinct patterns of H3K4me3 methylation associated with aberrations in gene expression in monocytes from patients with SLE [39]. Their results demonstrated that genes overexpressed in SLE tended to respond to H3K4me3 changes downstream of transcription start sites.

Our findings, as well the expanded understanding of gene regulation that has emerged in the past 10 years, suggest a new paradigm of SLE pathogenesis that includes complex interactions between the innate and adaptive immune systems that may emerge because of disordered transcriptional regulation in both lymphoid and myeloid cells. The field of functional genomics is demonstrating that transcription is a complex process that must be regulated and coordinated on a genome-wide basis to maintain normal cellular function [32]. For example, transcription factors do not simply bind to DNA independently from other proteins, but rather interact with one another in layers of complexity. This newer finding suggests that transcriptional and regulatory networks are created for complex biological processes, and that even small perturbations of this system (e.g., from genetic variance or environmentally-induced epigenetic alterations) could accumulate over time. These cumulative small perturbations result in significant disorders in the regulation and coordination of transcription, ultimately leading to the development of disease. These newer data suggest that complex disorders may be due less to "bad genes" than to faulty gene regulation $[40,41]$. Perhaps SLE, and many of the other conditions we refer to as "autoimmune diseases," may be better understood as a disease of disordered transcription.

It is important to keep in mind the limitations of our study. First, both Bentham et al. and Sun et al.
$[17,18]$ focused on regions of immunologic interest when performing GWAS, in that both groups used the Illumina Immunochip. The GWAS thus identified only selected genomic regions of specific immunologic interest that confer risk for SLE. It will be important to investigate whether additional risk loci would be revealed with a broadening of the query to genes that regulate chromatin access, or genes that regulate specific epigenetic processes (e.g., DNA methyl transferases, histone deacetylases, etc.).

In addition, as already mentioned briefly, enhancers appear to be cell-type specific and tissue specific. The enhancer marks used in this study for neutrophils and lymphocytes as mapped by the Roadmap Epigenomics project were detected in adult blood cells. There is the possibility that slightly different results could be obtained from cells in pediatric SLE patients. Thus, our results may not be generalizable or extrapolated, for example, to a pediatric population without further investigation. Indeed, we already know that the epigenomes of pathologically relevant cells may differ from epigenetic marks annotated in Roadmap data [42]. Coit et al. [40], for example, have shown that the methylome in $\mathrm{CD} 4^{+} \mathrm{T}$ cells of patients with SLE shows distinct differences from what is observed in healthy controls.

Moreover, the SLE patients included in the GWAS studies were generated from heterogeneous populations and most likely included patients with varying clinical manifestations. It is well known that SLE can affect different organ systems in the body with varying severity, and that treatment of these manifestations varies from milder immunosuppression with hydroxychloroquine alone to more aggressive immunosuppression with anti-neoplastic agents for disease control. Recently, Haddon et al. [43] demonstrated that pediatric SLE patients with kidney involvement possessed a different autoantibody profile than those without kidney involvement. Other groups then showed differences in expression levels of RNA and microRNAs in lupus nephritis biopsies [44, 45], suggesting that different clinical phenotypes may have individualized gene expression signatures. 
Table 3 Histone marks in the SNP linkage disequilibrium blocks in CD19 ${ }^{+}$B cells

\begin{tabular}{|c|c|c|c|c|c|c|}
\hline $\begin{array}{l}\text { GWAS index } \\
\text { SNP }\end{array}$ & Chr & $\begin{array}{l}\text { Linkage disequilibrium } \\
\text { blocks }\end{array}$ & $\begin{array}{l}\text { Number of H3K27ac } \\
\text { marks }\end{array}$ & $\begin{array}{l}\text { Number of H3K4me1 } \\
\text { marks }\end{array}$ & $\begin{array}{l}\text { Number of H3K4me3 } \\
\text { marks }\end{array}$ & $\begin{array}{l}\text { Enhancer marks (yes/ } \\
\text { no) }\end{array}$ \\
\hline rs10028805 & 4 & $102736456-102762581$ & 44 & 61 & 13 & Yes \\
\hline rs10036748 & 5 & $150457485-150461049$ & 15 & 25 & 14 & Yes \\
\hline rs10488631 & 7 & $128585616-128711874$ & 43 & 62 & 11 & Yes \\
\hline rs1059312 & 12 & $129277164-129288534$ & 33 & 66 & 1 & Yes \\
\hline rs10774625 & 12 & $111884608-112007756$ & 0 & 34 & 0 & Yes \\
\hline rs10807150 & 6 & $35154315-35278796$ & 71 & 110 & 33 & Yes \\
\hline rs10936599 & 3 & $169477506-169528523$ & 32 & 18 & 33 & Yes \\
\hline rs11644034 & 16 & $85967285-85980534$ & 49 & 106 & 23 & Yes \\
\hline rs11889341 & 2 & $191943742-191970120$ & 0 & 0 & 0 & No \\
\hline rs12022418 & 1 & $192521591-192535107$ & 0 & 0 & 0 & No \\
\hline rs1270942 & 6 & $31704294-32175415$ & 57 & 58 & 123 & Yes \\
\hline rs12802200 & 11 & $566936-567627$ & 0 & 0 & 0 & No \\
\hline rs1610555 & 18 & $67523453-67544046$ & 0 & 0 & 0 & No \\
\hline rs1801274 & 1 & $161470042-161479745$ & 0 & 8 & 0 & Yes \\
\hline rs1885889 & 13 & $100084234-100104106$ & 17 & 43 & 3 & Yes \\
\hline rs2009453 & 11 & $65399528-65405300$ & 0 & 12 & 0 & Yes \\
\hline rs223881 & 16 & 57386566-57317134 & 0 & 30 & 0 & Yes \\
\hline rs2286672 & 17 & $4706123-4712617$ & 1 & 7 & 7 & Yes \\
\hline rs2289583 & 15 & $75285114-75370012$ & 23 & 122 & 8 & Yes \\
\hline rs2305772 & 19 & $52021247-52034940$ & 2 & 35 & 11 & Yes \\
\hline rs2421184 & 5 & 158884119-158886939 & 0 & 18 & 0 & Yes \\
\hline rs2431697 & 5 & 159879978-159883217 & 0 & 2 & 0 & Yes \\
\hline rs2476601 & 1 & $114303808-114377568$ & 18 & 32 & 13 & Yes \\
\hline rs2663052 & 10 & $50045456-50081232$ & 0 & 1 & 0 & Yes \\
\hline rs2732549 & 11 & 35073852-35098193 & 6 & 47 & 0 & Yes \\
\hline rs2736340 & 8 & $11337587-11353000$ & 40 & 71 & 29 & Yes \\
\hline rs2941509 & 17 & $37885383-38077485$ & 235 & 468 & 84 & Yes \\
\hline rs3024505 & 1 & 206939904-206943968 & 0 & 48 & 0 & Yes \\
\hline rs34572943 & 16 & $31272353-31276811$ & 0 & 36 & 0 & Yes \\
\hline rs3768792 & 2 & 213871709-213890232 & 0 & 10 & 0 & Yes \\
\hline rs3794060 & 11 & $71138710-71203790$ & 10 & 28 & 22 & Yes \\
\hline rs4917014 & 7 & $50278187-50308811$ & 17 & 57 & 0 & Yes \\
\hline rs4948496 & 10 & $63803472-63819903$ & 80 & 101 & 17 & Yes \\
\hline rs61616683 & 22 & $39747050-39756650$ & 5 & 17 & 0 & Yes \\
\hline rs6568431 & 6 & 106574794-106597639 & 4 & 14 & 0 & Yes \\
\hline rs6740462 & 2 & $65654364-65667272$ & 1 & 20 & 27 & Yes \\
\hline rs6932056 & 6 & $138132123-138243700$ & 57 & 115 & 20 & Yes \\
\hline rs740840 & 12 & $6327008-63600683$ & 0 & 26 & 0 & Yes \\
\hline rs7444 & 22 & 21920817-21983260 & 14 & 88 & 10 & Yes \\
\hline rs7556469 & 1 & 198607998-198637582 & 47 & 81 & 26 & Yes \\
\hline rs7726414 & 5 & 133232663-13877357 & 540 & 1176 & 284 & Yes \\
\hline
\end{tabular}


Table 3 Histone marks in the SNP linkage disequilibrium blocks in CD19+ B cells (Continued)

\begin{tabular}{lllllll}
\hline rs7941765 & 11 & $128499000-128500215$ & 19 & 45 & 0 & Yes \\
rs849142 & 7 & $28162674-28200097$ & 45 & 120 & 0 & Yes \\
rs9462027 & 6 & $34563164-34828553$ & 95 & 171 & 41 & Yes \\
rs9652601 & 16 & $11164567-11207894$ & 31 & 82 & 0 & Yes \\
rs9782955 & 1 & $235907825-236041129$ & 38 & 71 & 15 & Yes \\
\hline
\end{tabular}

Linkage disequilibrium blocks were obtained from the 1000 Genomes Project pilot 1 and/or HapMap3 database Chr chromosome, GWAS genome-wide association studies, SNP single nucleotide polymorphism

Our results also have implications for the optimization of therapy in patients with SLE. Jiang et al. [20] demonstrated that response to treatment in JIA suggests that children on treatment for JIA can experience a long period of asymptomatic disease remission, but continue to have immune cell dysregulation. Our current treatments for SLE do not "normalize" immune cell function, as evidenced by continued periods of disease remission and flare. A better understanding of how epigenetic signatures drive gene expression signatures in SLE patients will allow us to better determine which patients with which SLE phenotypes will respond best to different treatments given their epigenetic profiles.

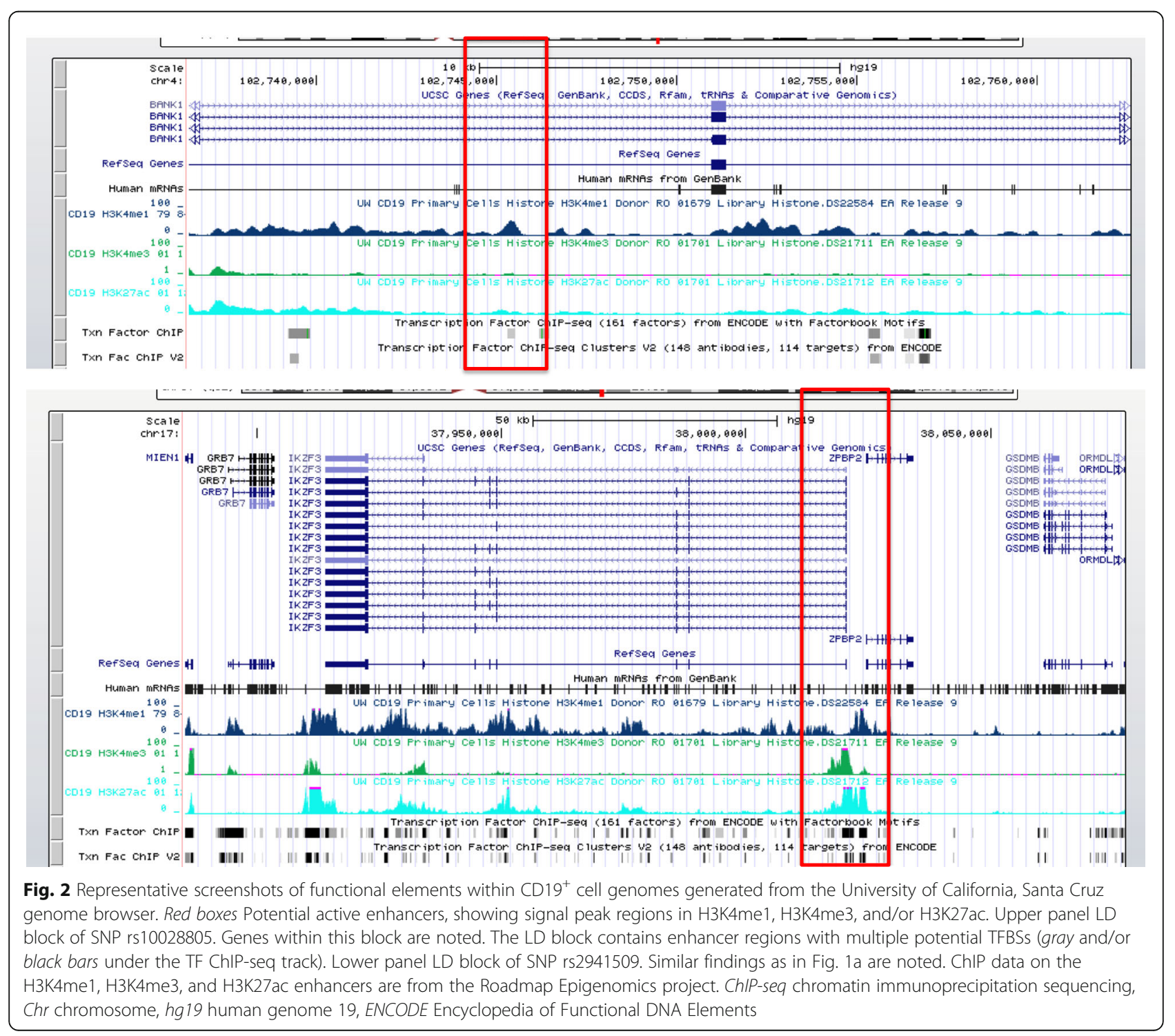


a

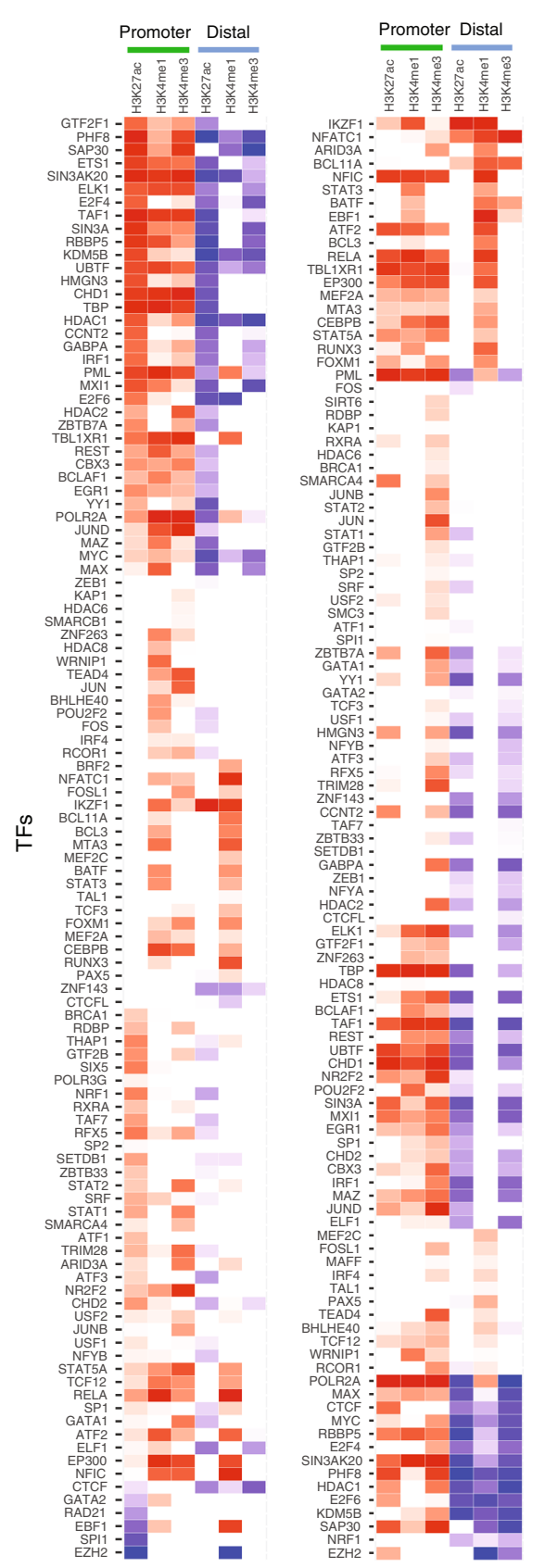

\section{C}

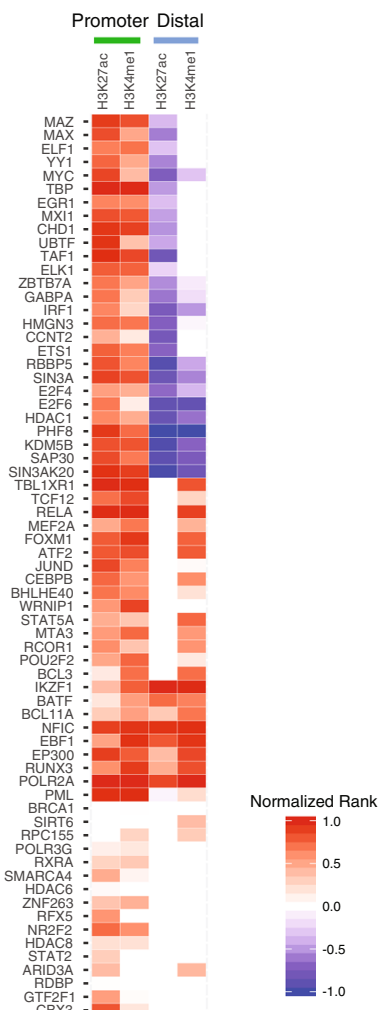

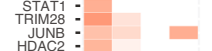

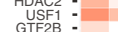

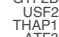

SATC:
BCAAF

SETRB

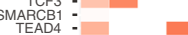

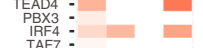

角 ATA

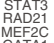

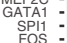

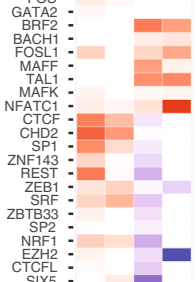

Fig. 3 Enrichment of TFBSs in enhancer regions. a Heatmap of TFBSs in H3K27ac, H3K4me1, and H3K4me3 peak regions in promoter and distal regions in $\mathrm{CD}_{1} 9^{+}$cells. $\mathbf{b}$ Heatmap of TFBS in H3K27ac, H3K4me1, and H3K4me3 peak regions in promoter and distal regions in $\mathrm{CD}^{+}$cells. $\mathbf{c}$ Heatmap of TFBSs in H3K27ac and H3K4me1 peak regions in promoter and distal regions in neutrophils. Normalized rank: >0 enrichment (red); $<0$ depletion (blue). TF transcription factor (Color figure online)

\section{Conclusion}

In this study, we have shown that disease-associated SNPs in SLE lie within LD blocks rich in functional elements regulating and coordinating gene transcription. These findings provide new insight into possible links between genetic and epigenetic risk factors for SLE.

\section{Additional file}

Additional file 1: Table S1. is presenting genes (a) and functional pathways (b), as identified through Panther, associated with SNPs in systemic lupus. (DOCX $16 \mathrm{~kb})$ 


\section{Abbreviations}

ChIP: Chromatin immunoprecipitation; ChIP-seq: Chromatin immunoprecipitation sequencing; FDR: False discovery rate; GWAS: Genome-wide association studies; JIA: Juvenile idiopathic arthritis; LD: Linkage disequilibrium; RNAseq: Ribnonucleotide sequencing; RT: Room temperature; SLE: Systemic lupus erythematosus; SNP: Single nucleotide polymorphism; TF: Transcription factor; TFBS: Transcription factor binding sites

\section{Acknowledgements}

The authors would like to thank Dr Kathleen O'Neil and Dr Betty Diamond for their critical comments.

\section{Funding}

This work was supported, in part, by R01-AR-060604 awarded to JNJ and by the Cohen Children's Medical Center Mentored Pediatric Service Line Grant for Early Career Investigators awarded to JSH-Y for data collection and interpretation.

\section{Availability of data and materials}

The datasets used and/or analyzed during the current study are available from the corresponding author upon reasonable request.

\section{Authors' contributions}

JSH-Y was involved in study conceptualization and design, data collection, and analysis through ENCODE and Roadmap for lymphocytes, wrote the first draft of the manuscript and performed revisions. LZ was responsible for data collection and analysis of ChIP-seq, ENCODE, and Roadmap data for neutrophils, and helped draft the manuscript. LPW helped analyze the data through ENCODE and Roadmap for lymphocytes and helped draft the manuscript. $\mathrm{KJ}$ and $\mathrm{YC}$ performed all wet laboratory experiments including sample processing, RNA purification, ascertainment of RNA purity, RNA labeling and hybridization procedures, as well as ChIP-seg experiments, and helped revise the manuscript. TL was involved in study conceptualization and design, and helped revise the manuscript. JNJ was involved in study conceptualization, design, and coordination, and wrote the first draft of the manuscript with JSH-Y. All authors read and approved the final manuscript.

\section{Competing interests}

The authors declare that they have no competing interests.

\section{Consent for publication}

Not applicable.

\section{Ethics approval and consent to participate}

This study was approved by the Institutional Review Board at the University at Buffalo (ID: MODCR00000009). Consent was obtained from the three adult patients to obtain neutrophil data. The need for approval and consent was waived for the data analysis in lymphocytes using publicly available online genome resources.

\section{Author details}

'Division of Pediatric Rheumatology, Steven and Alexandra Cohen Children's Medical Center, 1991 Marcus Avenue, Suite M100, Lake Success, NY 11042, USA. ${ }^{2}$ Department of Pediatrics, Hofstra-Northwell School of Medicine, Hempstead, NY 11549, USA. ${ }^{3}$ Department of Biochemistry, University at Buffalo, Buffalo, NY 14203, USA. ${ }^{4}$ Department of Pediatrics, University at Buffalo, Buffalo, NY 14203, USA. ${ }^{5}$ Department of Biochemistry, and Genetics, Genomics, and Bioinformatics Program, University at Buffalo, Buffalo, NY 14203, USA. ${ }^{6}$ Genetics, Genomics, and Bioinformatics Program, University at Buffalo, Buffalo, NY 14203, USA.

Received: 12 July 2016 Accepted: 2 November 2016 Published online: 01 December 2016

\section{References}

1. Truedsson L, Bengtsson AA, Sturfelt G. Complement deficiencies and systemic lupus erythematosus. Autoimmunity. 2007:40:560-6.

2. Schejbel L, Skattum L, Hagelberg S, Ahlin A, Schiller B, Berg S, et al. Molecular basis of hereditary C1q-deficiency revisited: identification of several novel disease-causing mutations. Genes Immun. 2011;12:626-34.
3. Stegert M, Bock M, Trendelenberg M. Clinical presentation of human C1q deficiency: how much of a lupus? Mol Immunol. 2015;67:3-11.

4. Jonsson G, Sjoholm AG, Truedsson L, Bengtsson AA, Braconier JH, Sturfelt G. Rheumatological manifestations, organ damage and autoimmunity in hereditary-C2 deficiency. Rheumatol (Oxford). 2007;46:1133-9.

5. Yang Y, Chung EK, Wu YL, Savelli SL, Nagaraja HN, Zhou B, et al. Gene copynumber variation and associated polymorphisms of complement component C4 in human systemic lupus erythematosus (SLE): low copy number is a risk factor for and high copy number is a protective factor against SLE susceptibility in European Americans. Am J Hum Genet. 2007:80:1037-54.

6. Yang Y, Lhotta K, Chung EK, Eder P, Neumair F, Yu CY. Complete complement components C4A and C4B deficiencies in human kidney diseases and systemic lupus erythematosus. J Immunol. 2004;173:2803-14.

7. Cervino AC, Tsinoremas NF, Hoffman RW. A genome-wide study of lupus: preliminary analysis and data release. Ann N Y Acad Sci. 2007;1110:131-9.

8. Harley JB, Alarcon-Riquelme ME, Criswell LA, Jacob CO, Kimberly RP, Moser $\mathrm{KL}$, et al. Genome-wide association scan in women with systemic lupus erythematosus identifies susceptibility variants in ITGAM, PXK, KIAA1542 and other loci. Nat Genet. 2008;40:204-10.

9. Hom G, Graham RR, Modrek B, Taylor KE, Ortmann W, Garnier S, et al. Association of systemic lupus erythematosus with C8orf13-BLK and ITGAMITGAX. N Engl J Med. 2008;358:900-9.

10. Maurano MT, Humbert R, Rynes E, Thurman RE, Haugen E, Wang H, et al. Systemic localization of common disease-associated variation in regulatory DNA. Science. 2012;337:1190-5.

11. Jiang K, Zhu L, Buck M, Chen Y, Carrier B, Liu T, et al. Disease-associated SNPs from noncoding regions in juvenile idiopathic arthritis are located within or adjacent to functional genomic elements of human neutrophils and CD4+ T cells. Arthritis Rheumatol. 2015;67:1966-77.

12. Blanco P, Pitard V, Viallard JF, Taupin JL, Pellegrin JL, Moreau JF. Increase in activated CD8+ $T$ lymphocytes expressing perforin and granzyme $B$ correlates with disease activity in patients with systemic lupus erythematosus. Arthritis Rheum. 2005;51:201-11.

13. Jacquemin C, Schmitt N, Contin-Bordes C, Liu Y, Narayanan P, Seneschal J, et al. OX40 ligand contributes to human lupus pathogenesis by promoting T follicular helper response. Immunity. 2015;42:1159-70.

14. Garcia-Romo GS, Caielli S, Vega B, Connolly J, Allantaz F, Xu Z, et al. Netting neutrophils are major inducers of type I IFN production in pediatric systemic lupus erythematosus. Sci Transl Med. 2011;3:73ra20. doi:10.1126/ scitranslmed.3001201.

15. Lood C, Blanco LP, Purmalek MM, Carmona-Rivera C, De Ravin SS, Smith CK, et al. Neutrophil extracellular traps enriched in oxidized mitochondrial DNA are interferogenic and contribute to lupus-like disease. Nat Med. 2016:22:146-53.

16. Nashi E, Wang $Y$, Diamond B. The role of B cells in lupus pathogenesis. Int J Biochem Cell Biol. 2010;42:543-50.

17. Bentham J, Morris DL, Cunninghame Graham DS, Pinder CL, Tombleson P, Behrens TW, et al. Genetic association analyses implicate aberrant regulation of innate and adaptive immunity genes in the pathogenesis of systemic lupus erythematosus. Nat Genet. 2015;47:1457-64.

18. Sun C, Molineros JE, Looger LL, Zhou XJ, Kim K, Okada Y, et al. High-density genotyping of immune-related loci identifies new SLE risk variants in individuals with Asian ancestry. Nat Genet. 2016;48:323-30.

19. Ghisletti S, Barozzi I, Mietton F, Polletti S, De Santa F, Venturini E, et al. Identification and characterization of enhancers controlling the inflammatory gene expression program in macrophages. Immunity. 2010;32:317-28

20. Jiang K, Frank M, Chen Y, Osban J, Jarvis JN. Genomic characterization of remission in juvenile idiopathic arthritis. Arthritis Res Ther. 2013;15:R100.

21. Zhang Y, Liu T, Meyer CA, Eeckhoute J, Johnson DS, Bernstein BE, et al. Model-based analysis of ChIP-seq (MACS). Genome Biol. 2008;9:R137.

22. Bernstein BE, Stamatoyannopoulos JA, Costello JF, Ren B, Milosavljevic A, Meissner A, et al. The NIH Roadmap Epigenomics Mapping Consortium. Nat Biotechnol. 2010;28:1045-8.

23. Edgar R, Domrachev M, Lash AE. Gene Expression Omnibus: NCBI gene expression and hybridization array data repository. Nucleic Acids Res. 2002;30:207-10.

24. Johnson AD, Handsaker RE, Pulit SL, Nizzari MM, O'Donnell CJ, de Bakker PI. SNAP: a web-based tool for identification and annotation of proxy SNPS using HapMap. Bioinformatics. 2008;24:2938-9. 
25. Pennacchio LA, Bickmore W, Dean A, Nobrega MA, Bejerano G. Enchancers: give essential questions. Nat Rev Genet. 2013;14:288-95.

26. Benayoun BA, Pollina EA, Ucar D, Mahmoudi S, Karra K, Wong ED, et al. H3K4me3 breadth is linked to cell identity and transcriptional consistency. Cell. 2014;158:673-88.

27. Absher D, Li X, Waite LL, Gibson A, Roberts K, Edberg J, et al. Hypomethylation of interferon genes and compositional changes to CD4+ T cell populations. PLoS Genet. 2013;9, e1003678.

28. Coit P, Yalavarthi S, Ognenovski M, Zhao W, Hasni S, Wren JD, et al. Epigenome profiling reveals significant DNA demthylation of interferon signature genes in lupus neutrophils. J Autoimmun. 2015;58:59-66.

29. ENCODE Project Consortium. An integrated encyclopedia of DNA elements in the human genome. Nature. 2012;489:57-74.

30. Farh KK, Marson A, Zhu J, Kleinewietfeld M, Housley WJ, Beik S, et al. Genetic and epigenetic fine mapping of causal autoimmune disease variants. Nature. 2015;518:337-43.

31. Bennett L, Palucka AK, Arce E, Cantrell V, Borvak J, Banchereau J, et al. Inteferon and granulopoeisis signatures in systemic lupus erythematosus blood. J Exp Med. 2003;197:711-23.

32. Komili S, Silver PA. Coupling and coordination in gene expression processes: a systems biology view. Nat Rev Genet. 2008;9:38-48.

33. Venter JC, Adams MD, Myers EW, Li PW, Mural RJ, Sutton GG, et al. The sequence of the human genome. Science. 2001;291:1304-51.

34. Lander ES, Linton LM, Birren B, Nusbaum C, Zody MC, Baldwin J, et al. Initial sequencing and analysis of the human genome. Nature. 2001;412:565.

35. Martin P, McGovern A, Orozco G, Duffus K, Yarwood A, Schoenfelder S, et al. Capture $\mathrm{Hi}-\mathrm{C}$ reveals novel candidate genes and complex long-range interactions with related autoimmune risk loci. Nat Commun. 2015;6:10069. doi:10.1038/ncomms 10069 .

36. Mohrs M, Blankespoor CM, Wang ZE, Loots GG, Afzal V, Hadeiba H, et al. Deletion of a coordinate regulator of type 2 cytokine expression in mice. Nat Immunol. 2001;2:842-7.

37. Dozmorov MG, Dominguez N, Bean K, Macwana SR, Roberts V, Glass E, et al. $B$ cell and monocyte contribution to systemic lupus erythematosus identified by cell-type-specific differential expression analysis in RNA-sea data. Bioinform Biol Insights. 2015;9:11-9.

38. Shi L, Zhang Z, Song L, Leung YT, Petri MA, Sullivan KE. Monocyte enhancers are highly altered in systemic lupus erythematosus. Epigenomics. 2015;7:921-35

39. Zhang Z, Shi L, Dawany N, Kelsen J, Petri MA, Sullivan KE. H3K4 trimethylation breadth at transcription start sites impacts the transcriptome of systemic lupus erythematosus. Clin Epigenetics. 2016;8:14. doi:10.1186/ s13148-016-0179-4.

40. Coit P, Ognenovski M, Gensterblum E, Maksimowicz-McKinnon K, Wren JD, Sawalha AH. Ethnicity-specific epigenetic variation in naïve CD4+ T cells and the susceptibility to autoimmunity. Epigenetics Chromatin. 2015;8:49. doi:10. 1186/s13702-015-0037-1.

41. Stamatoyannopoulos JA. What does our genome encode? Genome Res. 2012;22:1602-11.

42. Seumois G, Chavez L, Gerasimova A, Lienhard M, Omran N, Kalinke L, et al. Epigenomic analysis of primary human $T$ cells reveals enhancers associated with Th2 memory cell differentiation and asthma susceptibility. Nat Immunol. 2014;15:777-88.

43. Haddon DJ, Diep VK, Price JV, Limb C, Utz PJ, Balboni I. Autoantigen microarrays reveal autoantibodies associated with proliferative nephritis and active disease in pediatric systemic lupus erythematosus. Arthritis Res Ther. 2015:17:162. doi:10.1186/s13075-015-0682-6

44. Krasoudaki E, Banos A, Stagakis E, Loupasakis K, Drakos E, Sinatkas V, et al. Micro-RNA analysis of renal biopsies in human lupus nephritis demonstrates up-regulated miR-422a driving reduction of kallikrein-related peptidase 4. Nephrol Dial Transplant. 2015 [Epub ahead of print].

45. Ichinose K, Ushigusa T, Nishino A, Nakashima Y, Suzuki T, Horai Y, et al. Lupus nephritis IgG induction of calcium/calmodulin-dependent protein kinase IV expression in podocytes and alteration of their function. Arthritis Rheumatol. 2016;68:944-52.

\section{Submit your next manuscript to BioMed Central and we will help you at every step:}

- We accept pre-submission inquiries

- Our selector tool helps you to find the most relevant journal

- We provide round the clock customer support

- Convenient online submission

- Thorough peer review

- Inclusion in PubMed and all major indexing services

- Maximum visibility for your research

Submit your manuscript at www.biomedcentral.com/submit
Biomed Central 